\title{
The Signature of ENSO in the Northern Hemisphere Midlatitude Seasonal Mean Flow and High-Frequency Intraseasonal Variability
}

\author{
W. May and L. Bengtsson \\ With 16 Figures \\ Received February 26, 1998 \\ Revised July 15, 1998
}

\begin{abstract}
Summary
The impact of pronounced positive and negative sea surface temperature (SST) anomalies in the tropical Pacific associated with the El Niño/Southern Oscillation (ENSO) phenomenon on the atmospheric circulation in the Northern Hemisphere extratropics during the boreal winter season is investigated. This includes both the impact on the seasonal mean flow and on the intraseasonal variability on synoptic time scales. Moreover, the interaction between the transient fluctuations on these times scales and the mean circulation is examined. Both data from an ensemble of five simulations with the ECHAM3 atmospheric general circulation model at a horizontal resolution of T42 each covering the period from 1979 through 1992 and operational analyses from ECMWF for the corresponding period are examined. In each of the simulations observed SSTs for the period of investigation are given as lower boundary forcing, but different atmospheric initial conditions are prescribed.

The simulations with ECHAM3 reveal a distinct impact of the pronounced SST-anomalies in the tropical Pacific on the atmospheric circulation in the Northern Hemisphere extratropics during El Niño as well as during La Niña events. These changes in the atmospheric circulation, which are found to be highly significant in the Pacific/North American as well as in the Atlantic/European region, are consistent with the essential results obtained from the analyses. The pronounced SST-anomalies in the tropical Pacific lead to changes in the mean circulation, which are characterized by typical circulation patterns. These changes in the mean circulation are accompanied by marked variations of the activity of the transient fluctuations on synoptic time scales, that are changes in both the kinetic energy on these time scales and the atmospheric transports of momentum and heat accomplished by the short baroclinic waves. The synoptic disturbances, on the other
\end{abstract}

hand, play also an important role in controlling the changes in the mean circulation associated with the ENSO phenomenon. They maintain these typical circulation patterns via barotropic, but counteract thern via baroclinic processes.

The hypothesis of an impact of the ENSO phenomenon in the Atlantic/European region can be supported. As the determining factor the intensification (reduction) of the Aleutian low and the simultaneous reduction (intensification) of the Icelandic low during El Niño and during La Niña events, respectively, is identified. The changes in the intensity of the Aleutian low during the ENSO-events are accompanied by an alteration of the transport of momentum caused by the short baroclinic waves over the North American continent in such a way that the changes in the intensity of the Icelandic low during El Niño as well as during La Niña events are maintained.

\section{Introduction}

Over the last decade the pronounced variations of the sea surface temperatures (SSTs) in the tropical Pacific associated with El Niño/Southern Oscillation (ENSO) phenomenon (e.g., Philander, 1990) with their far reaching effects on the atmospheric circulation in various parts of the globe (e.g., Walker and Bliss, 1932, 1937; Bjerknes, 1969; Ropelewski and Halpert, 1987) have been the subject of intense research. One reason for this strong interest are the implications of the ENSO phenomenon for seasonal forecasting, since the changes in the large-scale circulation in the Northern Hemisphere extratropics 
associated with the ENSO phenomenon can potentially be predicted applying empirical (e.g., Barnston, 1994) as well as dynamical methods (e.g., Palmer and Anderson, 1994).

Whereas the impact of the ENSO phenomenon on the atmospheric circulation in the Pacific/ North American region is well known (e.g., Horel and Wallace, 1981; Livezey and Mo, 1987), is its impact on the circulation over the Atlantic and Europe still under discussion (e.g., Fraedrich, 1994). A few previous studies (e.g., van Loon and Madden, 1981; van Loon and Rogers, 1981; Fraedrich and Müller, 1992) have identified a connection between climate anomalies in the Atlantic/European sector and the ENSO phenomenon, but the impact was found to be much weaker than in the Pacific/North American region and also not as robust.

Numerical general circulation models (GCMs) generally reproduce the observed impact of the El Niño phenomenon on the large-scale circulation, particularly in the Pacific/North American region realistically (e.g., Lau, 1985; Hoerling et al., 1992; Bengtsson et al., 1996). In these simulations SST-anomalies typical of an El Niño or a La Niña event have been prescribed as lower boundary forcing. The results, however, depend to some extent on the characteristics of the particular GCM, in particular the parameterizations of convection and of the exchange processes in the atmospheric boundary layer (e.g., Hoerling et al., 1992). The model used in their study has, for instance, a tendency to produce excessive precipitation in the tropics due to the characteristics of the model's convection scheme. This may cause the systematic model error in the zonal wind component with an enhancement of the westerly winds in the tropics and a reduction in the subtropical regions. This error is of the same order as the anomalies typically observed during an El Niño event.

Most of the diagnostic work on the extratropical atmospheric response to the pronounced SST-anomalies in the tropical Pacific associated with the ENSO phenomenon has concentrated on the impact on the mean circulation, that is the socalled stationary response, which is generally described via seasonal means. But only a few papers have discussed the non-stationary or socalled transient response, that is the impact of these pronounced SST-anomalies on the atmo- spheric variability on sub- or intraseasonal time scales. Hansen et al. (1989) and Fraedrich and Müller (1993), for instance, noticed a change in the spectral distribution of the contribution of transient fluctuations to the intraseasonal variability in the Northern Hemisphere midlatitudes during EI Niño as well as during La Niña events. Fraedrich and Müller (1992) found a shift in the stormtrack in the European region depending on the phase of ENSO. Starting out from the region of cyclogenesis southeast of Greenland the cyclones tend to follow a northern route over Iceland and Scandinavia during La Niña events, but a southern route over Scotland, central Europe and the Baltic states during El Niño events. Recently Straus and Shukla (1997) described in further detail variations of the high-frequency variability (on time scales between 2 and 10 days) in the Pacific/North American region associated with El Niño events. Renwick and Wallace (1996) reported on a relationship between blocking over the north Pacific and the ENSO phenomenon. They identified about $70 \%$. more days of blocking in the Bering Strait during La Niña events than during El Niño events for the period 1951 through 1994.

In the present paper we therefore undertake a comprehensive study of the impact of the ENSO phenomenon (El Niño as well as La Niña events) on the seasonal mean flow and on the intraseasonal variability on synoptic time scales in the Northern Hemisphere extratropics during the boreal winter season. Moreover, we study the interaction between the transient fluctuations on these time scales and the mean circulation. This is done in order to investigate, to which extent these fluctuations maintain or counteract the anomalous circulation patterns associated with the selected ENSO-events. Our paper reaches in several aspects beyond the aforementioned study by Straus and Shukla (1997). Our study includes, for instance, both El Niño and La Niña events. Further we do not confine our study to the Pacific/North American region but extend it to the whole Northern Hemisphere extratropics, so that we can also comment on the impact of the ENSO phenomenon on the circulation in the Atlantic/European region. We use both data from an ensemble of five simulations with an atmospheric GCM covering the period from 1979 
through 1992 and operational analyses from the European Centre for Medium-Range Weather Forecasts (ECMWF) for the corresponding period. We consider this particular period as very suitable, since it includes three complete cycles of El Niño and La Niña events. In each of the five simulations observed SSTs for the period of investigation have been given as lower boundary forcing, but different atmospheric initial conditions have been prescribed. This allows for an assessment of the external variability caused by variations of the SSTs compared to the natural variability, leading to an estimate of the potential predictability of the changes in the atmospheric circulation due to pronounced variations of the SSTs.

The paper is organized as follows: In section 2 we describe the data used in our study. In section 3 we specify the criterion for separating the data into periods affected by an El Niño or a La Niña event, respectively, and describe the characteristics of the selected ENSO-events. Subsequently we investigate the extratropical response during the selected ENSO-events, both the stationary (section 4) and the transient (section 5) response. In section 5 we also discuss the role of the transient fluctuations in maintaining the changes in the large-scale circulation associated with those ENSO-events. Concluding remarks follow in section 6 .

\section{Data}

The model employed is the ECHAM3 atmospheric GCM at a horizontal resolution of $\mathrm{T} 42$ and 19 vertical levels (DKRZ 1992). The model has been developed at the Max-Planck-Institute for Meteorology for simulating the global present day climate and a possible global change in climate due to enhanced emissions of greenhouse gases. It is based on the global forecasting system that is used at ECMWF, but several major changes have been made, in particular to the physical parameterizations in order to make the model suitable for climate simulations. For a detailed description of the model we refer to Roeckner et al. (1992) or Bengtsson et al. (1996).

We have performed five individual simulations with ECHAM3 over a period of approx. 14 years each. In each simulation a sequence of observed monthly mean values of the SSTs and of the sea- ice extent for a global ocean have been given as lower boundary forcing, but different atmospheric initial conditions have been prescribed. These data have been derived from observed monthly mean values of the SSTs and the sea-ice extent for the period September 1979 to December 1992. For the period 1979 to 1988 we have used the so-called AMIP-dataset (Gates, 1992) and for the subsequent years data from NMC/ CAC (Reynolds, 1988). The model data have been archived two times daily at 00 and 12 UTC.

As observational data we use operational analyses from ECMWF. The data have been available for the period September 1979 through December 1992 once daily at 00 UTC. For the purposes of our study we have reduced the data to $\mathrm{T} 42$, the same horizontal resolution as the simulations. A thorough discussion of the quality of these data is given in Trenberth (1992).

\section{Characteristics of Selected ENSO-Events}

In the period of investigation between 1979 and 1992 we have identified three complete cycles of negative and succeeding positive ST-anomalies in the eastern part of the tropical Pacific basin, that is the so-called Niño-3-region (e.g., Kousky et al., 1994). We select the ENSO-events according to the occurrence of pronounced SST-anomalies in this region, so that we consider the boreal winter seasons including December, January and February in 1982/83, 1986/87 and 1991/92 to be affected by an El Niño or warm ENSO-event and in $1980 / 81,1984 / 85$ and $1988 / 89$ by a La Niña or cold ENSO-event. The other seven winters (1970/80, 1981/82, 1983/84, 1985/86, 1987/88, $1989 / 90,1990 / 91$ ) have been assigned to the control cases.

Figure 1 shows the spatial distribution of the SST-anomalies for the three selected El Niño and La Niña events, respectively. The anomalies have been computed with respect to the long-term seasonal mean for the period between 1979 and 1992. According to this the strongest positive anomalies occur during the El Niño event in $1982 / 83$, the maximum anomalies of about $3.0^{\circ} \mathrm{C}$ are located between $100^{\circ}$ and $130^{\circ} \mathrm{W}$ along the equator. During the other two warm ENSO-events the anomalies are weaker $\left(\approx 1.4^{\circ} \mathrm{C}\right.$ in $1986 / 87$ and $\approx 2.2^{\circ} \mathrm{C}$ in $1991 / 92$ ), but the maximum deviations are to be found further west 


\section{El Niño events}
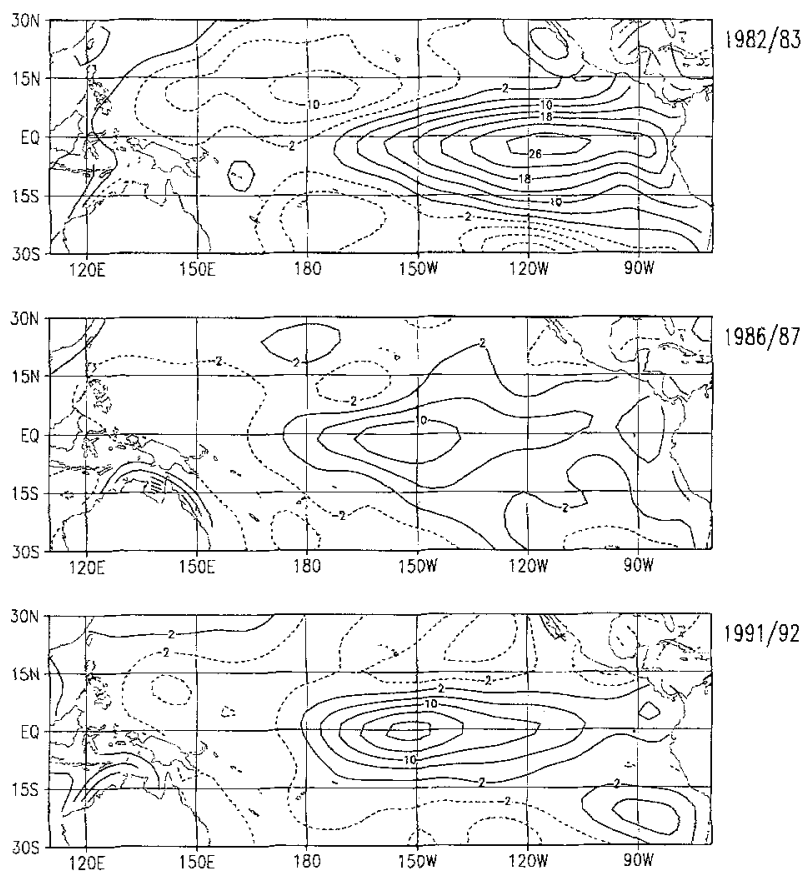

\section{La Niña events}
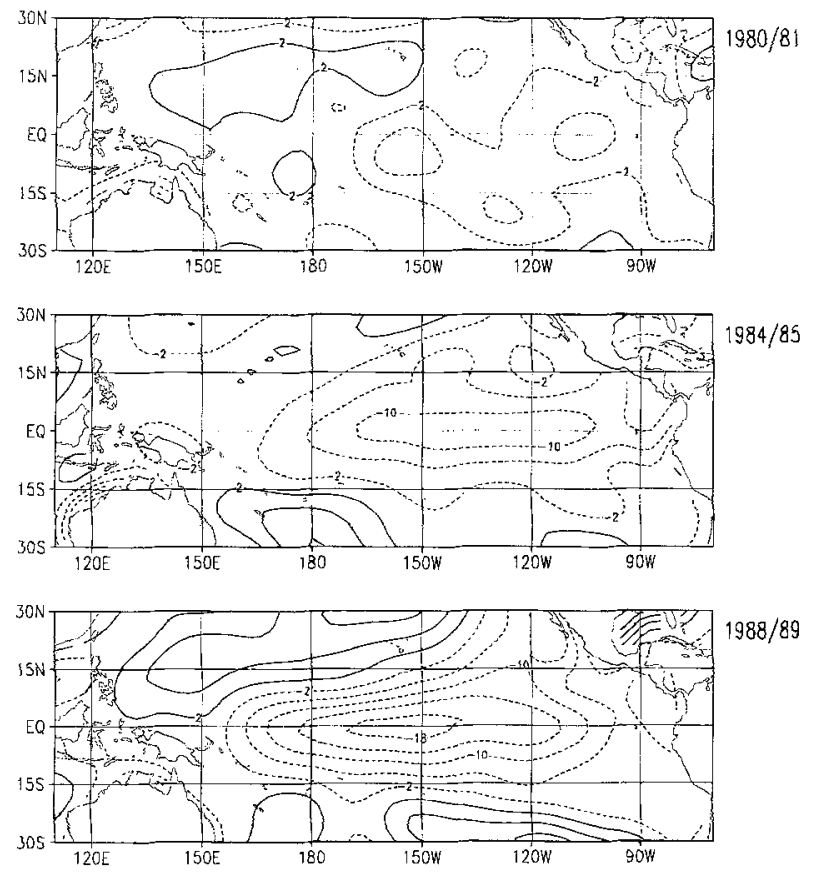

Fig. 1. Anomalies of the seasonal mean sea surface temperatures during boreal winter in 1982/83, 1986/87 and 1991/92 (El Niño events) and during boreal winter in 1980/81, 1984/85 and 1988/89 (La Niña events) in [0.1 $\left.{ }^{\circ} \mathrm{C}\right]$. The contour interval is $0.4^{\circ} \mathrm{C}$

in the central tropical Pacific between $140^{\circ}$ and $170^{\circ}$ W. During the La Niña event in 1988/89 the spatial structure of the SST-anomalies resembles that for the two El Niño events in 1986/87 and $1991 / 92$ except for the opposite sign. Maximum negative anomalies are about $2.2^{\circ} \mathrm{C}$. During the cold ENSO-event in 1984/85 maximum anomalies of approx. $1.4{ }^{\circ} \mathrm{C}$ are located further east, similar to the preceding El Niño event in 1982/ 83. But also during the relatively weak La Niña event in 1980/81 we find negative anomalies of up to $1.0^{\circ} \mathrm{C}$ in the entire eastern tropical Pacific.

These pronounced variations of the SSTs in the tropical Pacific lead to a displacement of the areas with strong convection and hence intense rainfall. During an El Niño event, for instance, the Intertropical Convergence Zone (ITCZ) approaches the equator and the South Pacific Convergence Zone moves northeastward (Liebmann and Hartmann, 1982). Then these two zones coincide over the western tropical Pacific, and the region of strong convection reaches along the equator well into the area east of the dateline. The simulations with ECHAM3 (the panels show ensemble means obtained from the set of five simulations) reveal this characteristic displacement of the two convergence zones during the two El Niño events in 1986/87 and 1991/92 (Fig. 2). The spatial distributions of the anomalies of the outgoing long-wave radiation (OLR) during these two periods show a pronounced enhancement of convection and thereby an increase of precipitation over the central tropical Pacific and a reduction over Indonesia. In 1991/ 92 the maximum negative anomalies are located about $20^{\circ}$ further east than in $1986 / 87$. In the eastern tropical Pacific region additional convection occurs just north of the equator, whereas further poleward the convection is reduced. The marked negative deviations over the central Pacific and the positive ones further west indicate a displacement of the ascending branch of the Walker-circulation from the Indonesian archipelago into the area over the central tropical Pacific during these two episodes. In 1982/83, when maximum SST-anomalies are to be found further east, the simulations reveal a general intensification of convection along the equator over the entire Pacific basin. Maximum negative OLRanomalies are located between $110^{\circ}$ and $140^{\circ} \mathrm{W}$ 

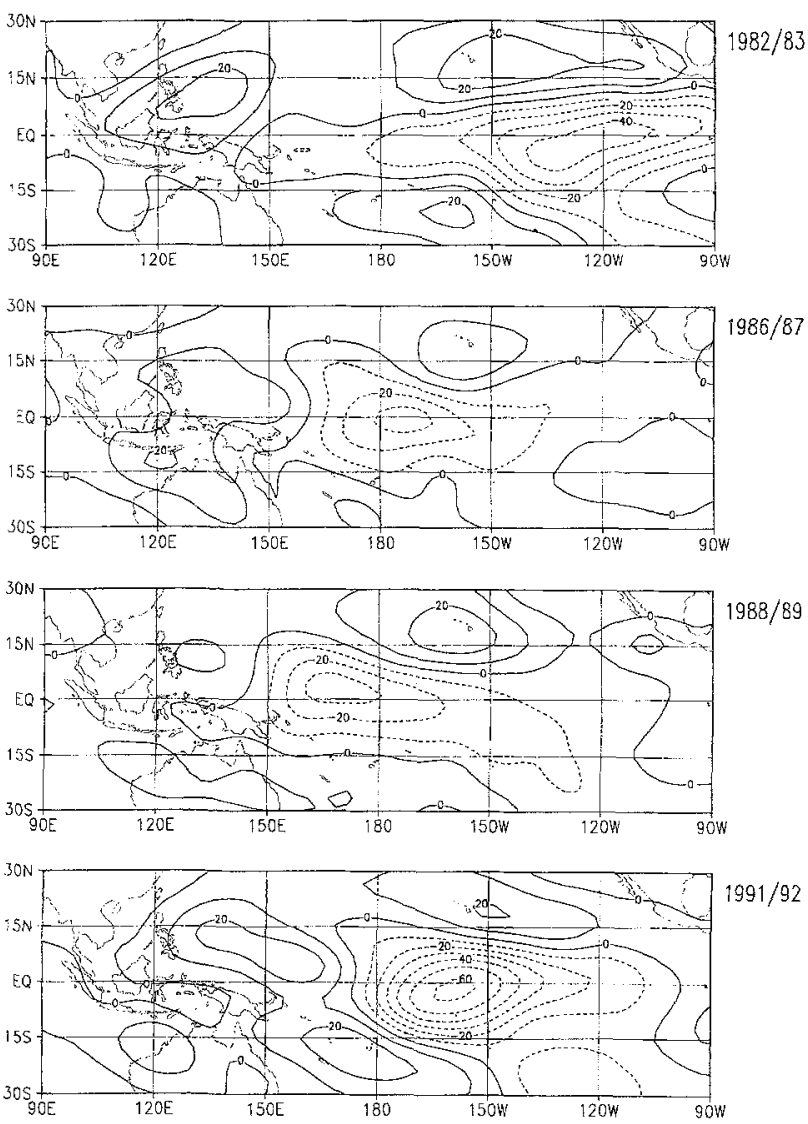

Fig. 2. Anornalies of the seasonal mean outgoing long-wave radiation during boreal winter in 1982/83, 1986/87, 1988/ 89 and 1991/92 obtained from the simulations with ECHAM3. The contour interval is $10 \mathrm{Watts} / \mathrm{m}^{2}$. The values for 1988/89 (La Niña event) are multilplied by a factor of -1

in coincidence with rather strong positive SSTanomalies in this area. During the selected La Niña events the simulations show a reduction of convection and, hence, precipitation along the equator over the entire Pacific basin. Further away from the equator, in particular in the region of the ITCZ over the eastern Pacific and also over Indonesia the convection is enhanced. During the two recent cold ENSO-events in 1984/85 (not shown here) and 1988/89 the most pronounced reduction of convection is to be found in the ascending branch of the Walker-circulation west of the dateline.

For the three selected El Niño events and the strong La Niña event in 1988/89 the overall location of the positive and negative OLRanomalies as simulated by the model is in rather good agreement with observations (Fig. 3). With
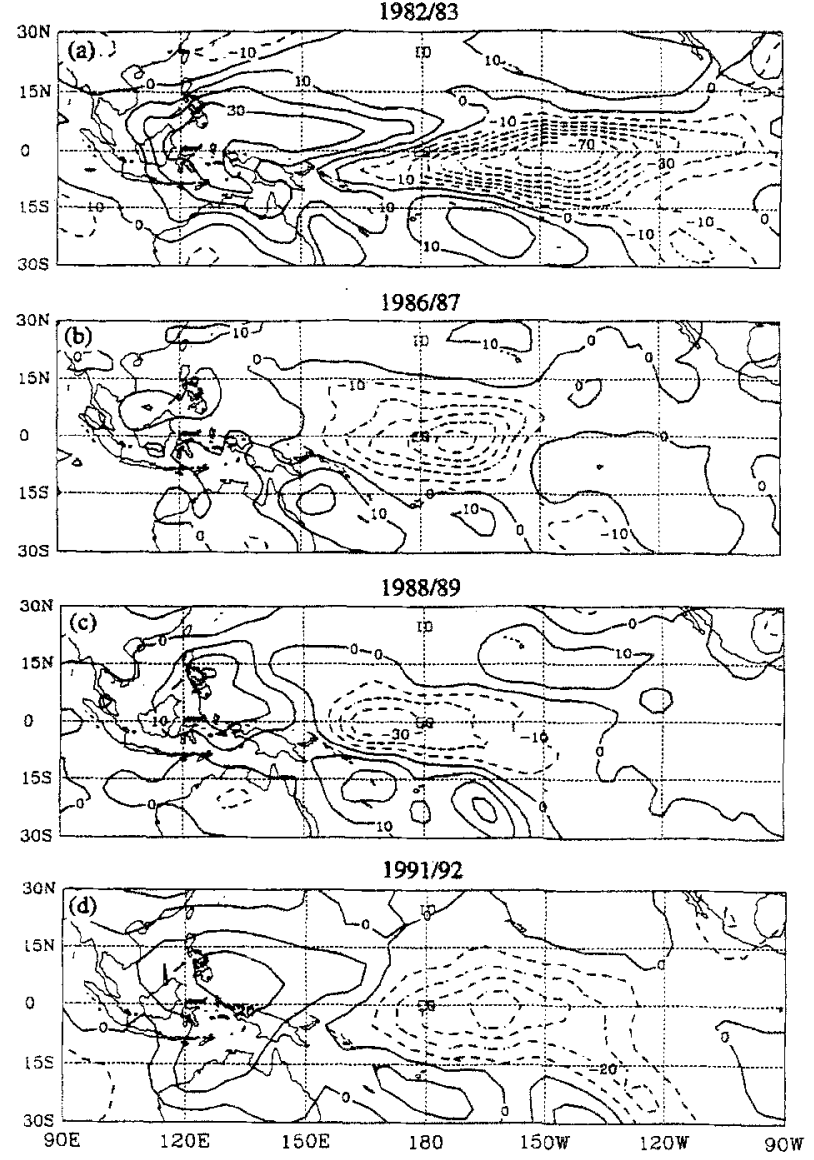

Fig. 3. As Fig. 2, but for observational data. (from Hoerling and Ting, 1994)

respect to the magnitude, however, we find some discrepancies for the two El Niño events in 1986/ 87 and 1991/92. The observations indicate a stronger increase of convection over the tropical Pacific in 1986/87 than in 1991/92, whereas the simulations reveal the opposite in correspondence to the tendency given by the relative strength of the SST-anomalies during these periods (see Fig. 1). During the La Niña event in 1988/89 the simulations agree very well with the observations, whereas during the warm ENSO-event in 1982/83 the enhancement of convection over the eastern Pacific is clearly underestimated by the model. Besides, the maximum negative OLR-anomalies occur about $20^{\circ}$ further east than in the observations. One should, however, be aware of the fact that OLR is used as a proxy for deep convection and that the 
OLR-data over the eastern tropical Pacific may be erroneous due to the enclosure of cirrus clouds (e.g., Zebiak, 1990).

\section{Stationary Response During ENSO-Events}

In this section we investigate the impact of the pronounced SST-anomalies in the tropical Pacific region associated with the ENSO phenomenon on the mean circulation in the Northern Hemisphere extratropics. For that purpose we take a look at the seasonal means of the geopotential height in $500 \mathrm{hPa}$ and of the zonal wind component in $300 \mathrm{hPa}$ in boreal winter including December, January and February.

\subsection{Geopotential Height}

\subsubsection{Composite Analysis}

Figure 4 shows composites of the seasonal mean geopotential height for the El Niño and the La Niña events and also the differences between these composites and the composite for the control cases obtained from the ensemble of five simulations with ECHAM3. The ENSO-events have been selected according to the criterion described in section 3. Hence the composites for the control cases include $35(=5 \times 7)$, the composites for the $\mathrm{El} \mathrm{Niño} \mathrm{and} \mathrm{the} \mathrm{La}$ Niña events $15(=5 \times 3)$ individual winters each. In addition to the differences themselves their

\section{EI Niño}

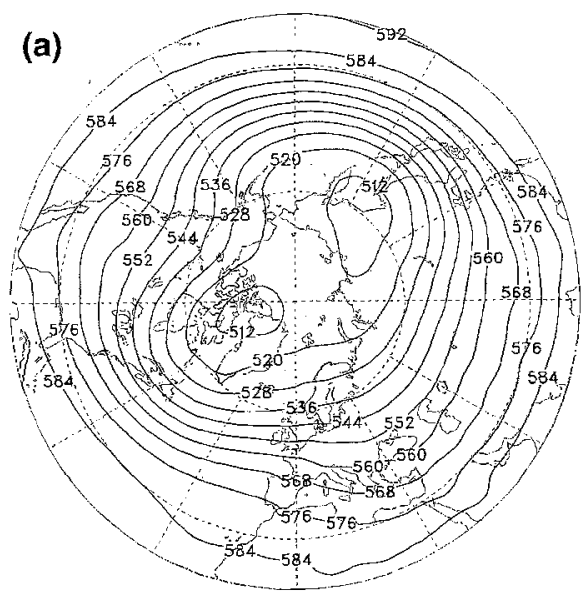

\section{El Niño - Ctrl}

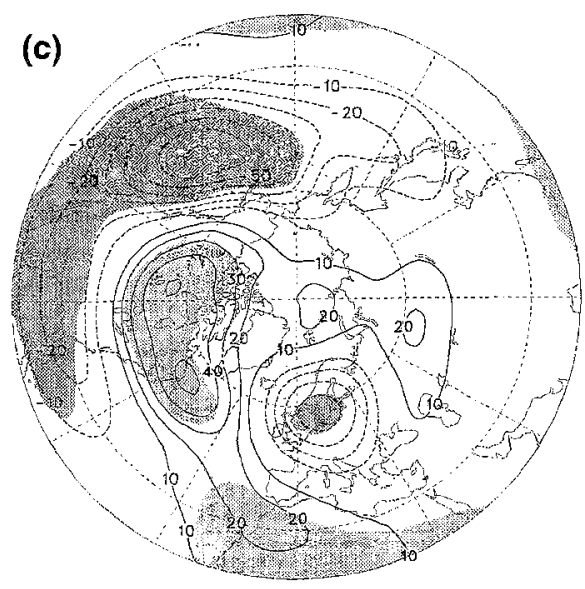

\section{La Niña}

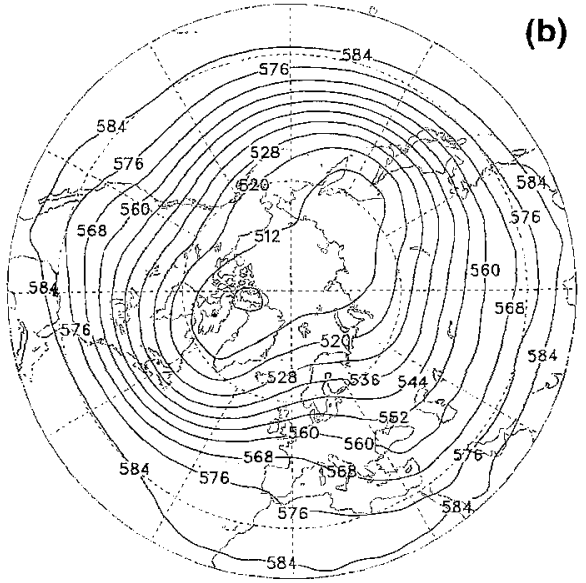

La Niña - Ctrl

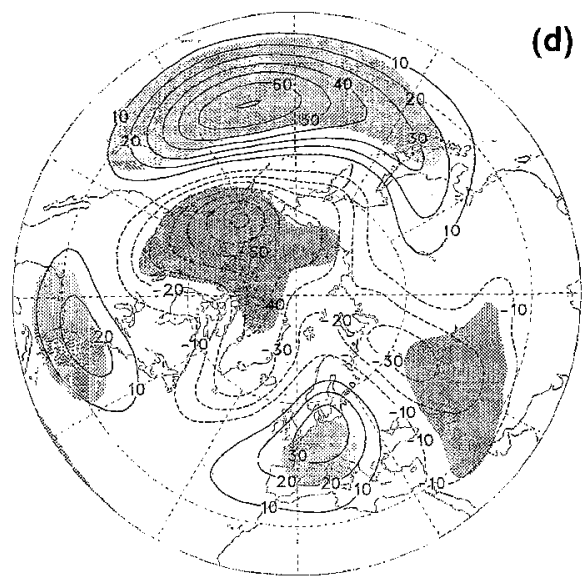

Fig. 4. Seasonal means of the geopotential height in $500 \mathrm{hPa}$ during boreal winter obtained from the simulations with ECHAM3 for the El Niño (a) and the La Niña events (b) in [gpdm]. The contour interval is $80 \mathrm{gpm}$. Also the differences between the El Niño events and the control cases $(c)$ and between the La Niña events and the control cases (d). The contour interval is $10 \mathrm{gpm}$. The significance of these differences on the $97.5 \%$-level is indicated by the shading. Positive significant differences are marked by the light, negative ones by the dark shading 
significance on the $97.5 \%$-level is indicated by the shading. Positive significant differences are marked by the light, negative ones by the dark shading. The significance has been obtained via a two-sided t-test (e.g., Essenwanger, 1986).

During El Niño events the geopotential height is reduced over the northern Pacific (Fig. 4c), and in upper-air field a trough appears over the eastern Pacific in coincidence with the intensification of the Aleutian low (Fig. 4a). Further downstream the ridge over western Canada is pronounced, whereas the geopotential height is reduced over the southeastern United States. The stationary response pattern corresponds very well to the positive phase of the TNH-pattern defined by Barnston and Livezey (1987), but also contains elements of the positive phase of the PNA-pattern defined by Wallace and Gutzler (1981). The TNH-pattern is shifted eastward with respect to the PNA-pattern in such a way that these two patterns are out of phase. It has a centre off the Pacific northwest coast of the U.S. at $40^{\circ}-$ $50^{\circ} \mathrm{N}, 125^{\circ}-140^{\circ} \mathrm{W}$, an centre of the opposite sign north of the U.S. Great Lakes at $45^{\circ}-55^{\circ} \mathrm{N}$, $80^{\circ}-90^{\circ} \mathrm{W}$ and a broad centre of the same sign as the centre over the Pacific east of Cuba. Therewith the stationary response to El Niño events in the Pacific/North American region as simulated by the model is consistent with numerous observations (e.g., van Loon and Madden, 1981; van Loon and Rogers, 1981; Livezey and Mo, 1987).

During La Niña events, on the other hand, we find the opposite pattern characterized by an increase of the geopotential height over the northern Pacific and a decrease over western North America (Fig. 4d). This indicates the weakening of the trough over the eastern Pacific and of the ridge over western North America, leading to a stronger zonal orientation of the mean flow in this area (Fig. 4b). Over the southeastern U.S. the geopotential height is reduced, so that the stationary response to $\mathrm{La}$ Niña events corresponds very well to the negative phase of the PNA-pattern, again in agreement with observations (e.g., van Loon and Madden, 1981). Hence the stationary response pattern during La Niña events as simulated by the model projects much more on the prominent mode of atmospheric variability in the Northern Hemisphere extratropics than during El Niño events
(May, 1996). The magnitude of the deviations from the control cases is roughly the same for the warm and cold ENSO-events

During El Niño events the increase of the geopotential height from North America extends into the area over the northwestern Atlantic leading to an increase of the atmospheric pressure, especially in the region south of Greenland (Fig. 4c). Over western and central Europe the geopotential height is reduced, but enhanced over eastern Europe, indicating the westward shift of the trough over eastern Europe. During La Niña events, on the other hand, the geopotential height over the northwestern Atlantic is reduced (Fig. $4 d$ ), in coincidence with the intensification of the Icelandic low. Further downstream the ridge over the eastern Atlantic and western Europe is pronounced, to be recognized by the increase of the geopotential height in this area.

Observations, however, reveal a somewhat different structure of the stationary response in the Atlantic/European region (e.g., van Loon and Rogers, 1981; Palmer and Anderson, 1994). These authors noticed a structure orientated in the north-south-direction similar to the North Atlantic Oscillation including the Icelandic low and the Azores high. During El Niño events the atmospheric pressure is found to be higher than during La Niña events over the northern Atlantic and northern Europe and lower in the area further south. Fraedrich and Müller (1992), who were able to include 26 EI Niño and 20 La Niña events in their study, observed surface pressure anomalies of the opposite sign in Europe depending on the phase of ENSO. During the warm ENSOevents a zonal band with relatively low pressure extends from Ireland across Europe as far east as the Black Sea (Fig. 5a). Further north over Scandinavia and the adjacent part of Russia the pressure is rather high. During the cold ENSOevents, on the other hand, relatively low pressure occurs over western and central Europe as well as over southern Scandinavia and rather high pressure further north (Fig. 5b).

A possible explanation for the discrepancy between the simulations with ECHAM3 and the observational results with regard to the stationary response is a systematic error of the model in simulating the mean flow in the Atlantic/ European region. In the simulations the ridge over western North America is not as pro- 

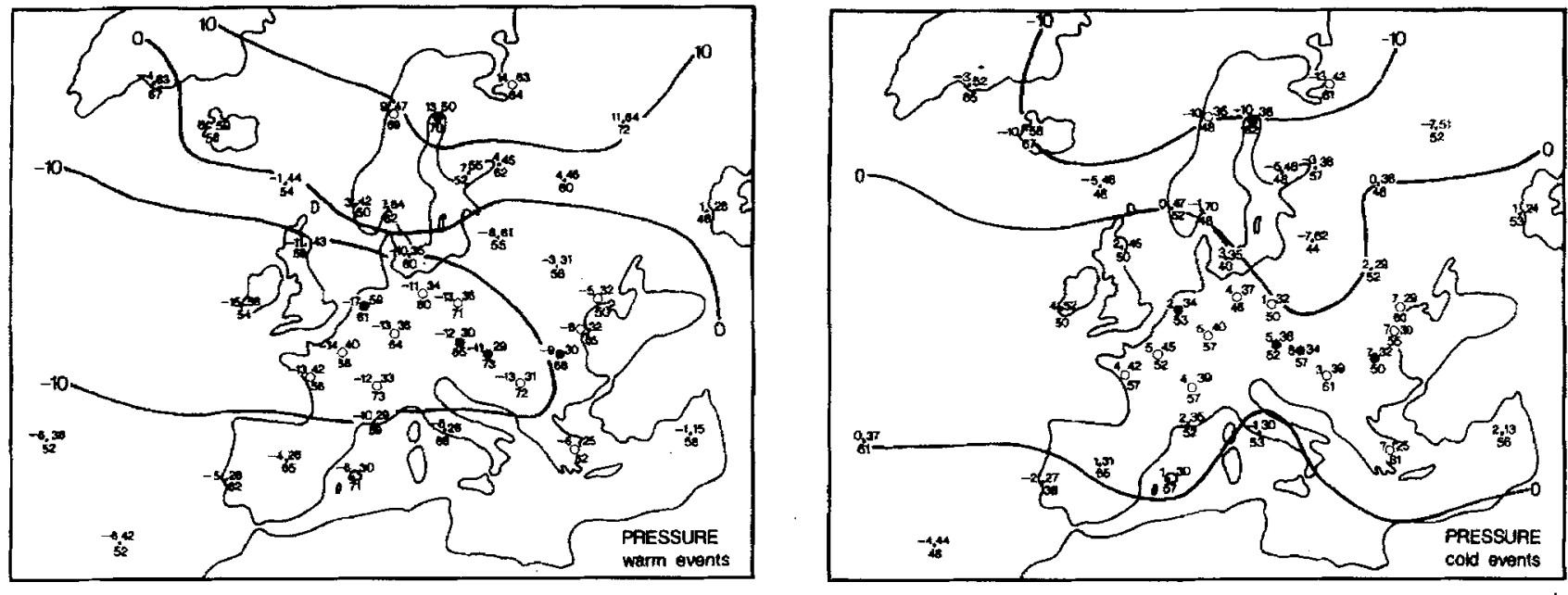

Fig. 5. Anomalies of the seasonal mean surface pressure for $26 \mathrm{E} 1 \mathrm{Niño}$ and $20 \mathrm{Niña}$ events during boreal winter. The numbers written at the stations are the deviation from the long-term mean (left) and the respective standard deviation (right) of the warm (cold) event ensemble in $[0.1 \mathrm{hPa}]$. Below the relative frequency indicates the percentage number of cold or warm event winters that realize the same positive or negative sign as given by the mean anomaly. (from Fraedrich and Müller, 1993)

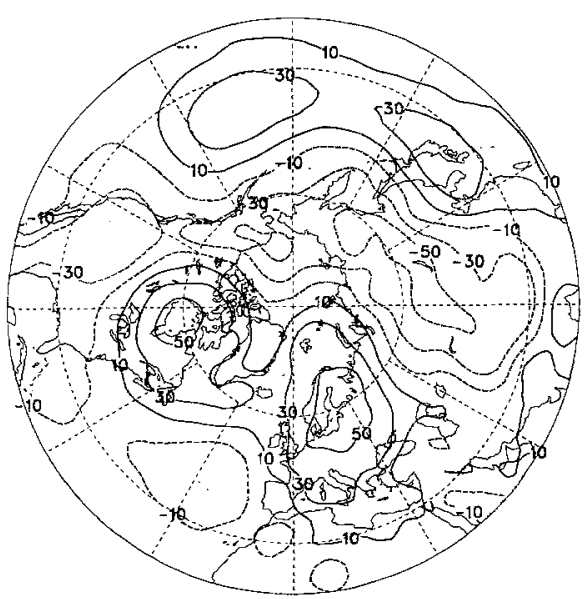

Fig. 6. Difference of the seasonal mean geopotential height in $500 \mathrm{hPa}$ (with the zonal mean removed) during boreal winter between the simulations with ECHAM3 and the ECMWF analyses. The contour interval is $20 \mathrm{gpm}$

nounced as in the analyses, and the trough over the eastern part of the continent is shifted downstream (Fig. 6). In addition, the trough over eastern Europe is too weak. This leads to a rather strong southerly component of the mean flow over the northeastern Atlantic, whereas the analyses indicate a prevailing westerly component of the mean flow in this area. This is probably mainly due to the mean orography prescribed in the model at a horizontal resolution of $\mathrm{T} 42$, so that the height of the governing mountain ranges in the Northern Hemisphere is underestimated. This, in turn, leads to an underestimation of the amplitude of the stationary wave with zonal wavenumber 3 , which determines the intensity and location of the troughs and ridges in the upper air flow in boreal winter. Another possible explanation is that the model tends to pick up the leading mode of atmospheric variability, which can easily be excited during ENSO-events, but not the other modes, which also contribute to the interannual variability in the area of interest. After all, the stationary response pattern over the Atlantic and Europe obtained from the simulations corresponds very well to the prominent mode of atmospheric variability in this area derived from both the analyses and the simulations (May, 1996).

The inspection of the stationary response pattern obtained from the ECMWF analyses reveals that in the period of investigation only two ENSO-events have a response similar to the "average" response patterns given in the simulations (see Fig. 4). That are the strong El Niño event in 1982/83 and the strong La Niña event in 1988/89 (Fig. 7). During the other ENSO-events at least the pattern in the Atlantic/European region is quite different from the result based on the model data, so that composites obtained from the analyses (not shown here) give almost no response in that area. In the following we will therefore in the case of the analyses present only 

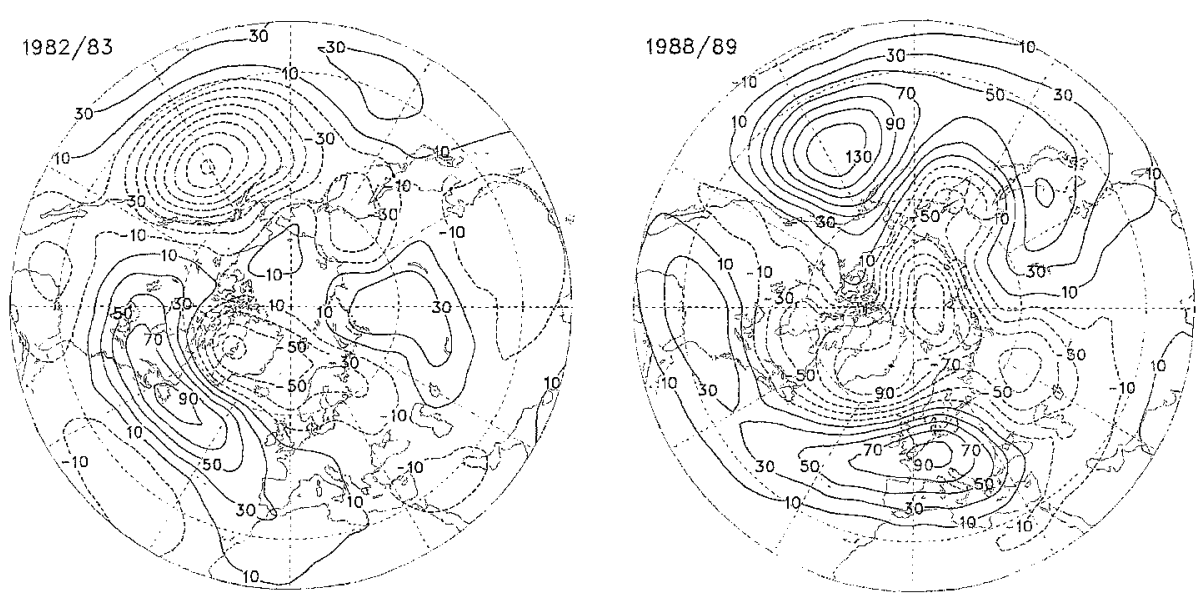

Fig. 7. Anomalies of the seasonal mean geopotential height in $500 \mathrm{hPa}$ during boreal winter in 1982/83 (El Niño) and 188/89 (La Niña) obtained from the ECMWF analyses. The contour interval is $20 \mathrm{gpm}$ anomalies for the two representative mentioned before.

The ECMWF re-analyses (e.g., Gibson et al., 1997), which are generally considered to be of better quality than the old operational analyses used in this study, show almost identical stationary response patterns in the Northern Hemisphere extratropics as the operational analyses, even in the early years of the analyses. Therefore we can be confident that our results do not reveal any erroneous anomalies and, hence, response patterns simply due to inhomogenities of the observational data.

\subsubsection{Potential Predictability}

The differences between the composites for the El Niño and La Niña events and the composite for the control cases are highly significant over most of the Pacific and North America and also in parts of the Atlantic/European region (see Fig. 4). This, however, does not say anything about the relative strength of the response to the marked SST-anomalies in the tropical Pacific associated with an ENSO-event or its predictability. Based on the ensemble of five simulations with the same SSTs but with different atmospheric initial conditions prescribed (see section 2) we assess the "external" variability or signal caused by variations of the SSTs and the "internal" variability due to internal atmospheric processes or noise. The ratio between the signal and the noise gives an estimate of the predictability of the externally forced variations. For a detailed description of the procedure we refer to Kumar and Hoerling (1995).
The distribution of the signal (Fig. 8a) reveals several maxima, which correspond to the locations of the maximum anomalies for the El Niño and the La Niña events (see Fig. 4). There is a strong maximum over the northeastern Pacific, but also over western Canada and the southeastern U.S. is the externally forced variability enhanced. Another well-defined maximum occurs over Europe, but in this region the externally forced variability is only about half as strong as over the northern Pacific. The distribution of the internal variability reveals also several maxima of similar magnitude (Fig. 8b). These are located in the regions of cyclogenesis near the Aleutian Islands and south of Greenland. The internal variability is also relatively strong over western and central Europe and in the European part of Russia.

The signal-to-noise ratio exceeds a value of 1 in most of the Pacific/North American region, in some areas a value of 1.88 (Fig. $8 \mathrm{c}$ ). The value of 1.88 , which has been obtained via a F-test with 13 degrees of freedom for the numerator and 65 $(=5 \times 13)$ for the denominator (e.g., Jenkins and Watts, 1968), corresponds to an error probability of less than $5 \%$. Apparently the change in the mean circulation due to variations of the SSTs can be predicted to a certain degree in the Pacific/North American region. One maximum of predictability is located over the southeastern part of the northern Pacific, another one further east over Mexico and the southern U.S. The signal is also stronger than the noise over western Canada and in the area east of Labrador. Also over Europe a well-defined maximum of predictability can be found, but the values of the 

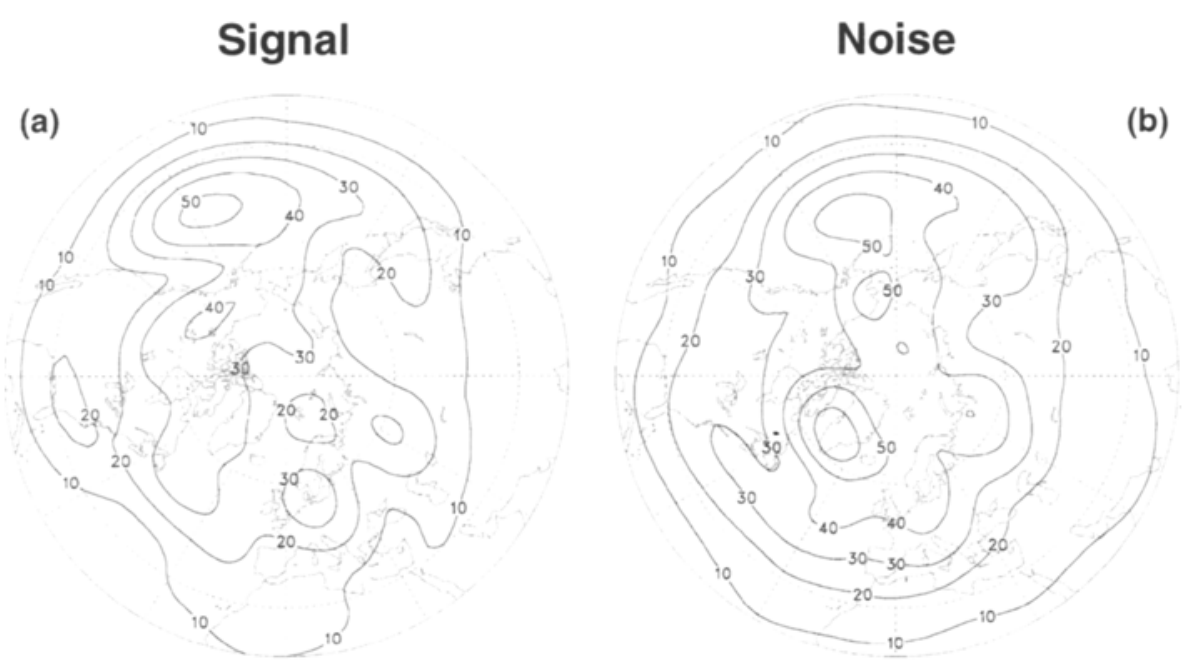

\section{Signal-to-Noise Ratio}

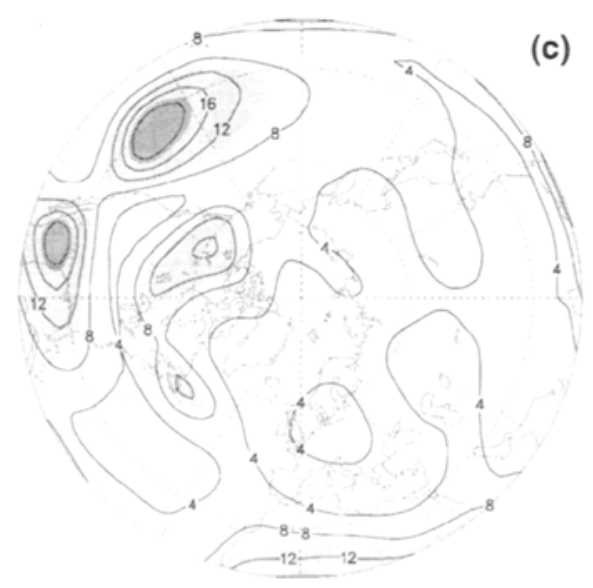

Fig. 8. Signal (a) and noise (b) of the seasonal mean geopotential height in $500 \mathrm{hPa}$ during boreal winter obtained from the simulations with ECHAM3. The contour interval is $10 \mathrm{gpm}$. Also the signalto-noise ratio (c), the values are multiplied by a factor of 10 . The contour interval is 0.4 . Values exceeding 1.0 are marked by the light, values exceeding 1.88 (see text) by the dark shading

signal-to-noise ratio are considerably smaller than 1. That means a change of the mean circulation can be expected in this region during an ENSO-event, but the natural variability is so strong that the response may be masked and, hence, not predictable. This result is consistent with the observation that the stationary response is by far more stable in the Pacific/North American region than downstream over the Atlantic and Europe (van Loon and Madden, 1981). In our study we have five ensemble members, a rather small number, so that the noise is somewhat over-estimated against the signal. According to Kumar and Hoerling (1995) the internal variability decreases nearly linearly with the number of realisations, whereas the externally forced variability hardly depends on the ensemble size. A more adequate larger number of ensemble members may therefore give some potential for prediction in the Atlantic/European region as well.

\subsection{Zonal Wind Component}

Figure 9 shows the composites of the seasonal mean zonal wind component in $300 \mathrm{hPa}$ (close to the height of the polar as well as of the subtropical jet stream) for the El Niño and the La Niña events and also the differences between these composites and the composite for the control cases obtained from the simulations with ECHAM3. During El Niño events the Pacific jet stream is strengthened, and its axis is shifted equatorward (Fig. 9c). In addition the core of the jet stream, which is located east of Japan, is extending further downstream over the southeastern part of the north Pacific (Fig. 9a). During La Niña events, on the other hand, the Pacific jet 

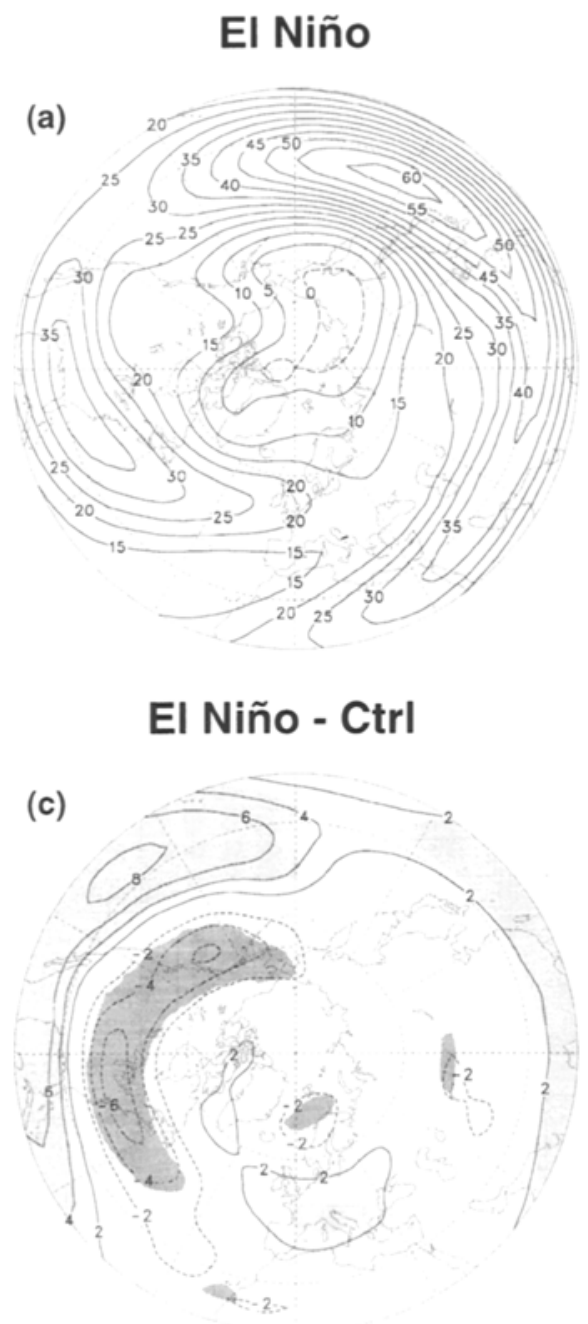
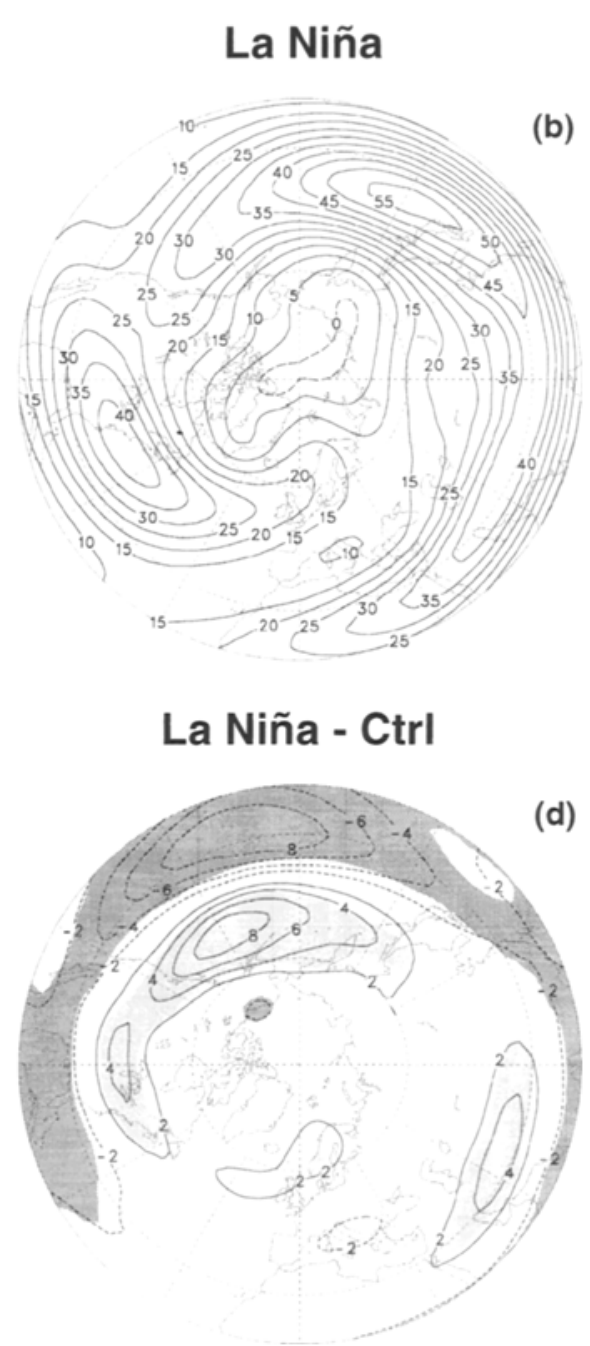

Fig. 9. As Fig. 4, but for the zonal wind component in $300 \mathrm{hPa}$. The contour interval is $5 \mathrm{~m} / \mathrm{s}(\mathrm{a}, \mathrm{b})$ and $2 \mathrm{~m} / \mathrm{s}(\mathrm{c}, \mathrm{d})$, respectively stream is shifted poleward, and relatively strong westerly winds occur over the northeastern part of the north Pacific. This is consistent with a change in the meridional pressure gradient over the northern Pacific during the different ENSOevents (see Fig. 4). During El Niño events the meridional pressure gradient is strongest over the southeastern part of the north Pacific, but during La Niña events in the area further north.

The Atlantic jet stream, on the other hand, is considerably reduced during El Niño (Fig. 9a) and enhanced during La Niña events (Fig. 9b). This is accompanied by an equatorward (poleward) shift of the jet stream's axis during the warm (cold) ENSO-events. These changes are consistent with a reduction and a strengthening of the meridional pressure gradient in this region during the warm and cold ENSO-events, respectively (see Fig. 4). In the European area the distributions reveal rather strong westerly winds over the northern part of the continent during La Niña and further south during El Niño events.

During the rather strong El Niño event in 1982/83 the ECMWF analyses (Fig. 10) reveal also a strengthening of the Pacific and a weakening of the Atlantic jet stream, but also relatively strong westerly winds over northern and central Europe. Hence the westerly wind anomalies in the European area are located somewhat further north than indicated in the simulations. One should, however, keep in mind that we are only looking at one particular El Niño event. During the strong La Niña event in 1988/89 the analyses and the simulations give a very similar response pattern, that is a weakening of the Pacific jet stream, but relatively strong westerly winds over Canada. Moreover, the Atlantic jet stream is enhanced during this period, and 

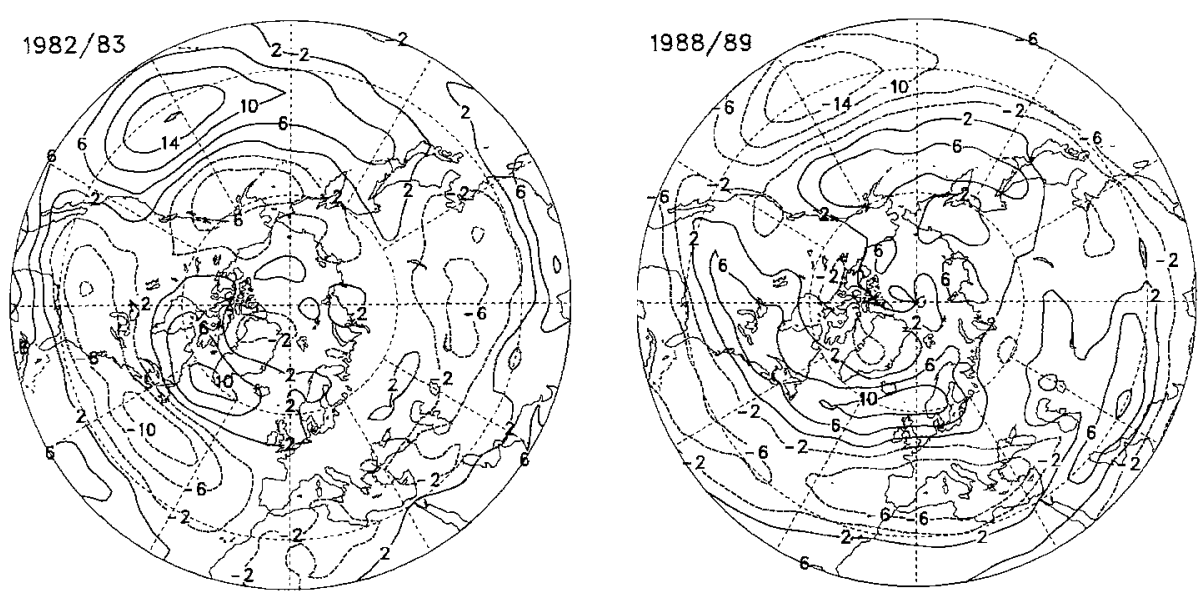

Fig. 10. As Fig. 7, but for the zonal wind component in 300 $\mathrm{hPa}$. The contour interval is $4 \mathrm{~m} / \mathrm{s}$

rather strong westerly winds occur also over Scandinavia.

\section{Transient Response During ENSO-Events}

In this section we investigate the impact of the pronounced SST-anomalies in the tropical Pacific region associated with the ENSO phenomenon on the intraseasonal variability in the Northern Hemisphere extratropics. We concentrate on the high-frequency part of the intraseasonal variability covering time scales between 2.5 and 6 days, which is caused by the short baroclinic waves (e.g., Blackmon, 1976). We have retained the transient fluctuations on these time scales by applying an appropriate band-pass filter. For that purpose the analyses (once daily) have been multiplied with 21 filter coefficients (Blackmon and Lau, 1980) and the data from the simulations (twice daily) with 31 filter coefficients (Blackmon, 1976).

\subsection{Kinetic Energy}

First we take a look at the band-pass filtered kinetic energy in $300 \mathrm{hPa}$. The regional maxima of this estimate of the activity of the synoptic waves define the stormtracks, which are linked to the preferred routes of extratropical cyclones (Wallace et al., 1988).

The distributions of the eddy kinetic energy reveal during both El Niño and La Niña events two characteristic maxima, one over the northern Pacific and one over Labrador with the latter one extending further downstream over the northern
Atlantic (Fig. 11). These two maxima, whose characteristics are affected by the ENSO phenomenon, represent the Pacific and the Atlantic stormtrack, respectively. During El Niño events the eddy kinetic energy is enhanced over the southern part of the north Pacific (Fig. 11c), but reduced further north, in particular over the Gulf of Alaska. This dipole structure corresponds to an equatorward shift of the Pacific stormtrack during the warm ENSO-events, especially in the area east of the dateline (Fig. 11a). Apparently the Pacific stormtrack adjusts to the change in the mean circulation, which is characterized by a pronounced trough over the eastern Pacific, leading to stronger meridional pressure gradient over the southeastern part of the north Pacific (see Fig. 4a). Our results are in very good agreement with those presented in Straus and Shukla (1997).

During La Niña events, on the other hand, the Pacific stormtrack is stronger than for the control cases (Fig. 11d). The eddy kinetic energy is significantly enhanced over the northern Pacific and western North America, in particular near the Aleutian Islands and south of Alaska. Further south the activity of the cyclones is reduced. At the same time cyclones reach more often into the western part of North America due to the stronger westerly flow. These results are in agreements with those in Lau (1988), who observed variations of the stormtrack associated with the prominent modes of the mean circulations, e.g. the PNA-pattern, so that the stormtracks are preferably located at or slightly downstream of the quasistationary troughs. 


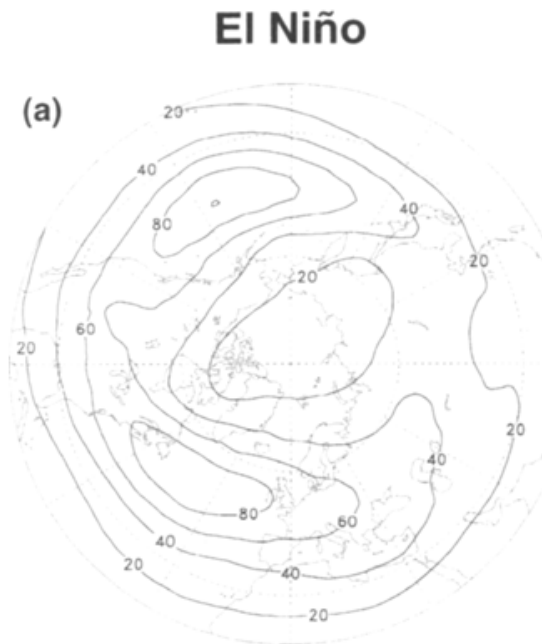

El Niño - Ctrl

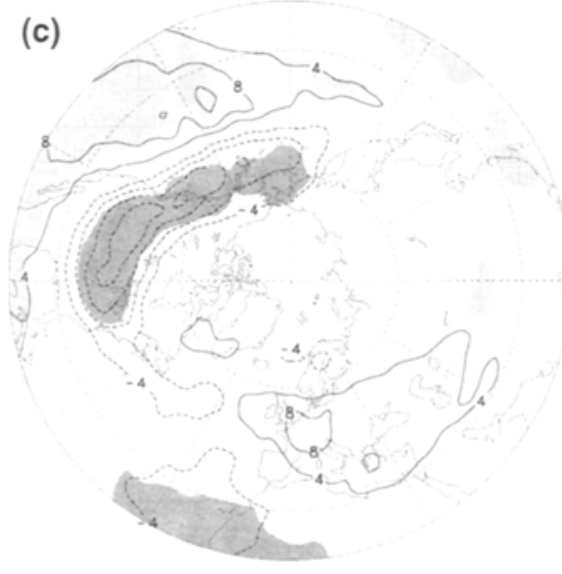

La Niña

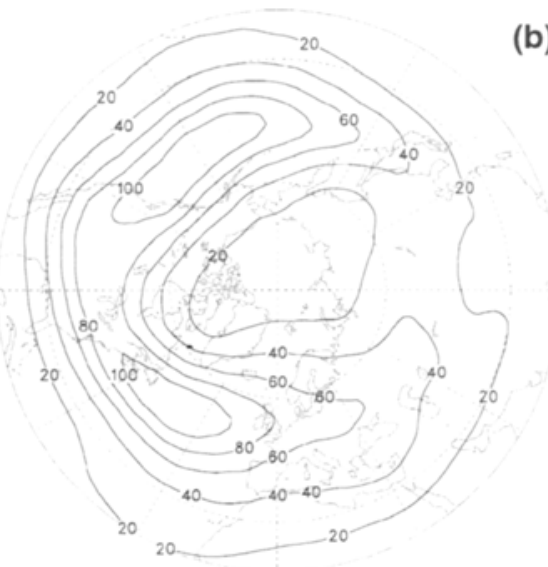

La Niña - Ctrl

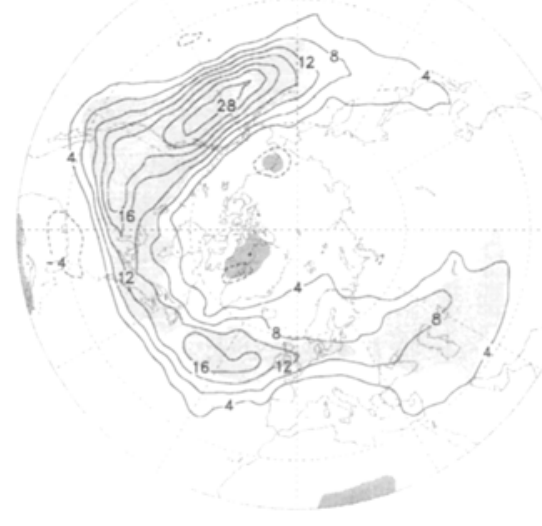

(d)

Fig. 11. As Fig. 4, but for the band-pass filtered kinetic energy in $300 \mathrm{hPa}$. The contour interval is $20 \mathrm{~m}^{2} / \mathrm{s}^{2}(a, b)$ and $4 \mathrm{~m}^{2} / \mathrm{s}^{2}$ (c, d), respectively
The Atlantic stormtrack is also stronger during La Niña events than for the control cases (Fig. 11d), but weaker during El Niño events (Fig. 11c). Different to the Pacific stormtrack, however, the Atlantic stormtrack does not shift in the meridional direction depending on the phase of ENSO. The changes in the intensity of the stormtrack reflect the variations in the meridional pressure gradient over the northwestern Atlantic set up by changes in the mean circulation in this area (see Fig. 4a and Fig. 4b). Further downstream we find an increase of the eddy kinetic energy over northern Europe during the cold ENSO-events, but over in the southern part of the continent during the warm events. Apparently the cyclones tend to take a northern route over Iceland and Scandinavia during La Niña events, whereas they are steered as far south as the Mediterranean during El Niño events. This agrees with observations of the occurrence of cyclones in Europe depending on the phase of ENSO (Fraedrich and Müller, 1992).

The ECMWF analyses (Fig. 12) show also an equatorward shift of the Pacific stormtrack during the El Niño event in 1982/83, especially in the area east of the dateline. The distribution reveals also an increase of the eddy kinetic energy over central Europe and the Mediterranean, but different to the simulations also over northern Europe. During the La Niña event in $1988 / 89$ the analyses and the simulations give a very similar response pattern. The Pacific stormtrack is enhanced and extending downstream into the western part of North America. The Atlantic 

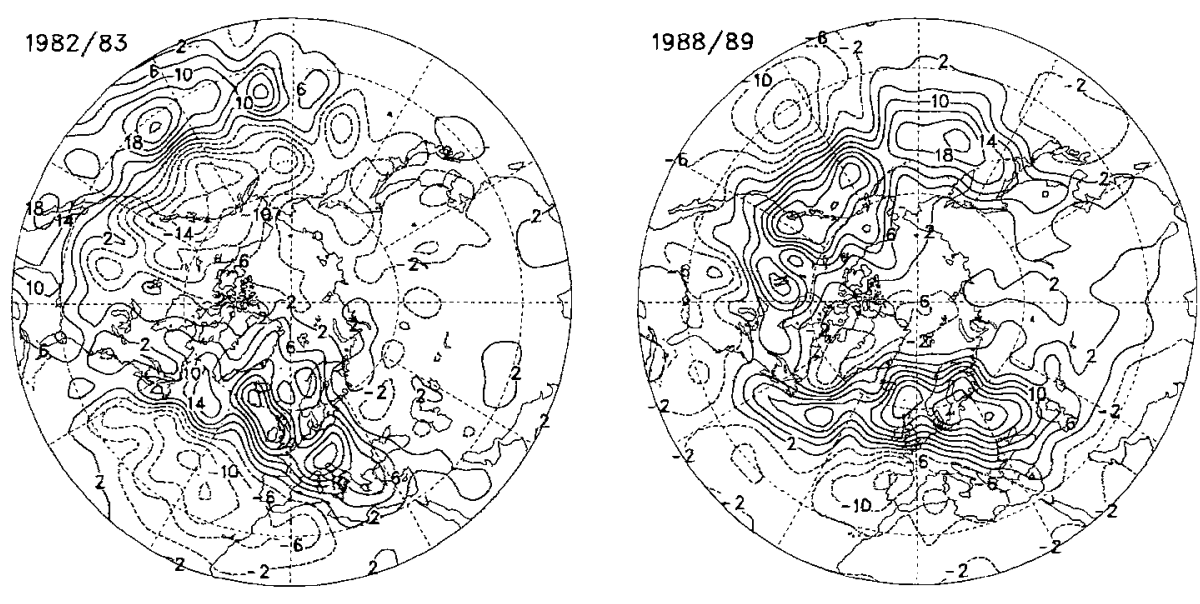

Fig. 12. As Fig. 7, but for the band-pass filtered kinetic energy in $300 \mathrm{hPa}$. The contour interval is $4 \mathrm{~m}^{2} / \mathrm{s}^{2}$

stormtrack is also intensified, and the eddy kinetic energy is considerably enhanced over the north Atlantic and northern Europe.

\subsection{Eliassen-Palm Flux Diagnostics}

In the following we describe the interactions between the transient fluctuations on synoptic time scales and the seasonal mean circulation by means of localized Eliassen-Palm (EP) flux diagnostics (Trenberth, 1986). This is done in order to investigate, to which extent these transient fluctuations maintain or counteract the changes in the large-scale circulation associated with the ENSO phenomenon (e.g., Lau and Holopainen, 1984). We distinguish between barotropic and baroclinic processes, which are included in the horizontal and the vertical component of the so-called E-vectors, respectively.

\subsubsection{Barotropic Processes}

Figure 13 shows composites of the horizontal component of the localized EP-flux in $300 \mathrm{hPa}$ by the transient fluctuations on time scales between
El Niño

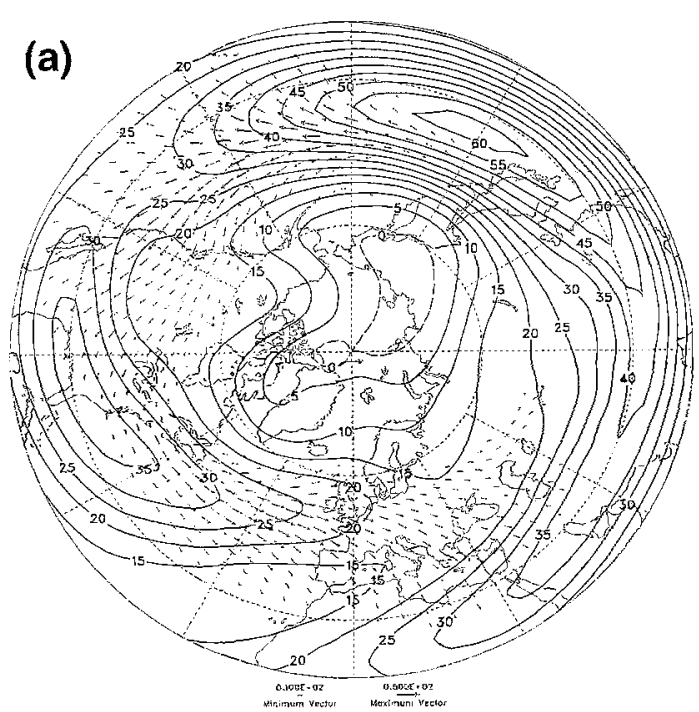

\section{La Niña}

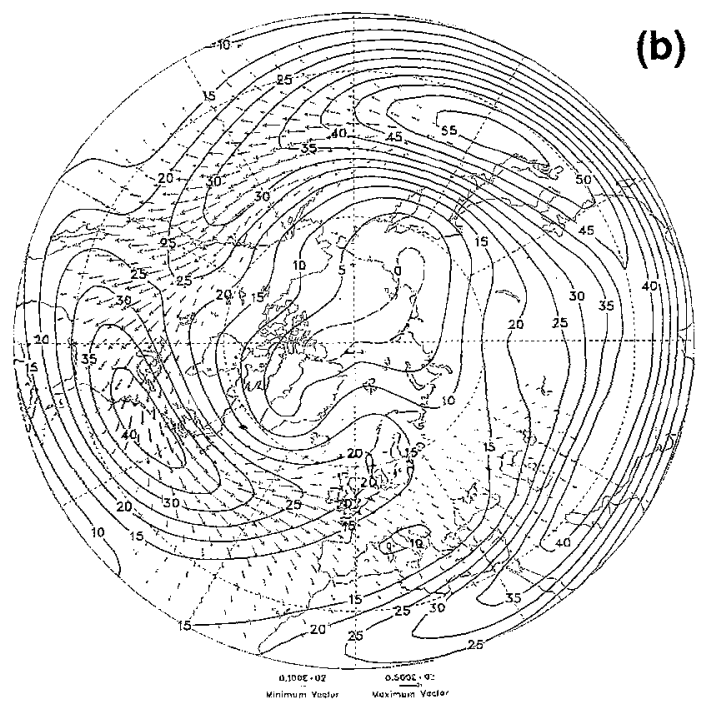

Fig. 13. Horizontal component of the band-pass filtered Eliassen-Palm fluxes (vectors) in $\left[\mathrm{m}^{2} / \mathrm{s}^{2}\right]$ and the seasonal means of the zonal wind component (contours) in $300 \mathrm{hPa}$ during boreal winter obtained from the simulations with ECHAM3 for the El Niño (a) and the La Niña events (b). The contour interval is $5 \mathrm{~m} / \mathrm{s}$ 


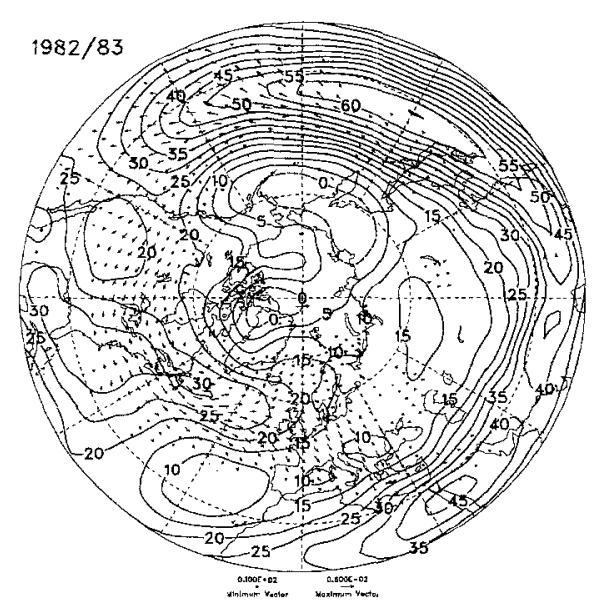

Fig. 14. As Fig. 13, but for ECMWF analyses during boreal winter in 1982/83 (El Niño) and 1988/89 (La Niña). Note the slightly different scale of the vectors as compared to the simulations: $60 \mathrm{~m}^{2} / \mathrm{s}^{2}$ ys. $50 \mathrm{~m}^{2} / \mathrm{s}^{2}$
2.5 and 6 days for the El Niño and the La Niña events obtained from the simulations with ECHAM3. The panels include also composites of the seasonal mean values of the zonal wind component in $300 \mathrm{hPa}$.

During both El Niño and La Niña events the distributions are characterized by a band of eastward orientated E-vectors. Starting out from the Pacific stormtrack the band extends downstream, includes the Atlantic stormtrack and reaches further downstream into the European region. The eastward orientation of the vectors indicates that the transient disturbances on synoptic time scales are associated with stronger fluctuations of the meridional than of the zonal wind component. In the areas north of the stormtracks the E-vectors are directed northward, further south they have a southward orientation, indicating the southward and northward transport of westerly momentum in these areas, respectively.

Due to the enhanced activity of the short baroclinic waves during La Niña events (see Fig. 11) the E-vectors are generally larger than during the cold (Fig. 13b) than during the warm ENSOevents (Fig. 13a). The most pronounced differences between the composites for the El Niño and the La Niña events can be found over North America, where the synoptic disturbances transport the westerly wind anomalies over the northeastern Pacific and the western part of North America downstream into the region of the Atlantic jet stream. The northward transport of westerly momentum in this area is very strong during La Niña events in coincidence with a particularly strong Atlantic jet stream, whereas rather weak fluxes of momentum occur over North American during El Niño events, when the strength of the jet stream is reduced. This result is confirmed by the ECMWF analyses (Fig. 14), according to which the E-vectors over North America are considerably stronger during the La Niña in 1988/89 than during the El Niño event in 1982/83. Another characteristic difference between the composites for the El Niño and the La Niña events is the intensification of the meridional transport of westerly momentum in the exit region of the Atlantic jet stream over the northwestern Atlantic during La Niña events (Fig. 13b). The analyses, however, reveal only rather small differences of the horizontal EP-flux between the two periods (1982/83 and 1988/89) in the European area (Fig. 14).

The divergence of the horizontal component of the EP-flux indicates, how the synoptic disturbances interact with the large-scale flow via barotropic processes. Apparently the short baroclinic disturbances tend to reinforce both the Pacific and the Atlantic jet stream and lead to a weakening of the westerly winds in the area north and south of the jet streams via barotropic processes (Fig. 15a and Fig. 15b). Rather large values of the divergence of EP-flux can also be found downstream of the cores of the jet streams in the area of the Pacific and the Atlantic stormtrack. Hence the synoptic disturbances lead to an extension of the strong westerly flow further downstream into the areas over the eastern Pacific and central Atlantic. Moreover, they strengthen the Atlantic jet stream in its entrance region over the central part of North America. 

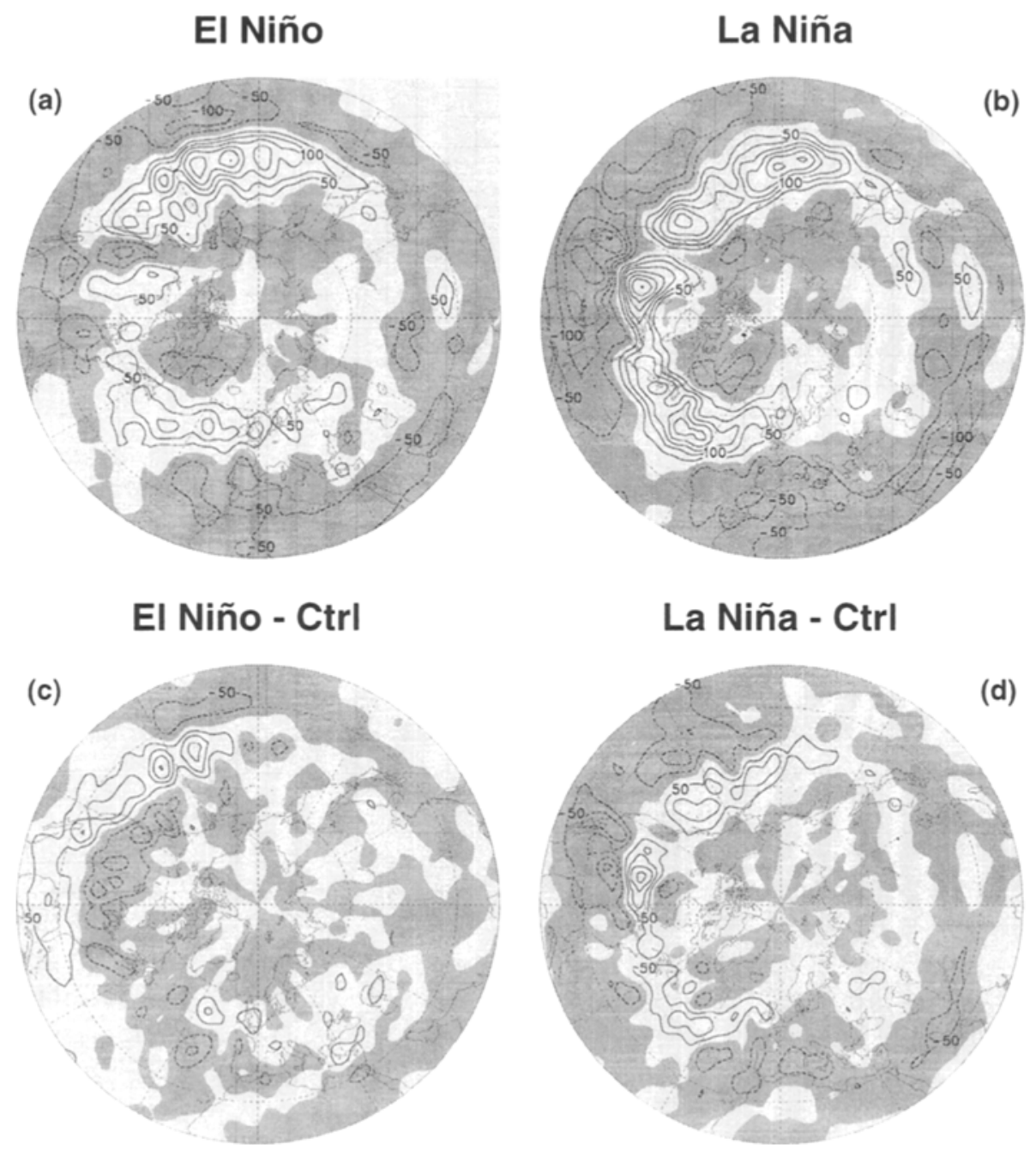

Fig. 15. Divergence of the bandpass filtered horizontal EliassenPalm flux in $300 \mathrm{hPa}$ during boreal winter obtained from the simulations with ECHAM3 for the EI Niño (a) and the La Niña events (b). Also the divergence derived from the differences between the El Niño events and the control cases (c) and between the La Niña events and the control cases (d). The contour interval is $50(\mathrm{~cm} / \mathrm{s}) /$ day. Positive values (strengthening of the seasonal mean westerly winds) are indicated by the light, negative ones (weakening of the seasonal mean westerly winds) by the dark shading
The distribution of the divergence obtained from the differences between the composites for the El Niño (Fig. 15c) or the La Niña events (Fig. $15 \mathrm{~d})$, respectively, and the composite for the control cases reveal that the synoptic disturbances generally tend to maintain the changes in the mean circulation associated with the ENSO phenomenon (see Fig. 9c and 9d) via barotropic processes. During La Niña events, for instance, the synoptic disturbances strengthen the westerly winds over the northeastern part of the north Pacific, in particular in the area west of the North American west coast (Fig. 15d). During El Niño events, on the other hand, the short baroclinic waves lead to a strengthening of the westerly winds in the regions further south (Fig. 15c). This agrees with the results by Straus and Shukla (1997), who show the tendency in the mean zonal wind component implied by the convergence of the high-frequency vorticity flux.
In the entrance region of the Atlantic jet stream over central North America we find a very pronounced strengthening of the westerly winds during La Niña events, but a rather weak amplification during El Niño events, resulting in an intensification of the Atlantic jet stream during the cold ENSO-events and in a reduction during the warm events. Also further downstream is the forcing by the baroclinic waves pronounced during La Niña events. The synoptic disturbances enforce the westerly wind anomalies over the northern Atlantic and northern Europe during La Niña events, whereas they support the westerly wind anomalies over the southern part of the continent during El Niño events. This corresponds to the results by Fraedrich et al. (1993), according to which the short baroclinic waves play an important role in maintaining the anomalous circulation patterns associated with extremes of the European climate. 

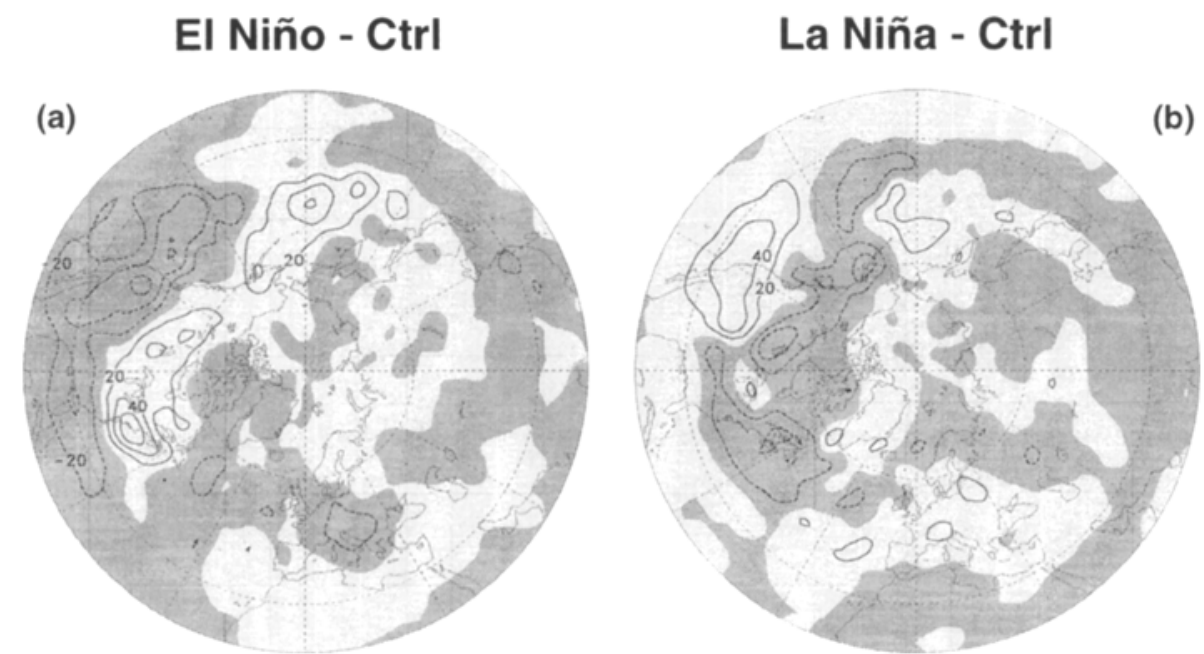

Fig. 16. Divergence of the band-pass filtered vertical Eliassen-Palm flux during boreal winter derived from the differences between the El Niño events and the control cases (a) and between the La Niña events and the control cases (b) according to the simulations with ECHAM3. The contour interval is $20(\mathrm{~cm} / \mathrm{s}) /$ day. Positive values (strengthening of the seasonal mean westerly winds) are indicated by the light, negative ones (weakening of the seasonal mean westerly winds) by the dark shading

Due to their rather noisy character we do not present distributions of the divergence of the horizontal EP-flux obtained from the ECMWF analyses for the two ENSO-events in 1982/83 and 1988/89, which have been discussed in further detail in the preceding sections.

\subsubsection{Baroclinic Processes}

The divergence of the vertical component of the localized EP-flux, on the other hand, indicates, how the synoptic disturbances interact with the large-scale circulation via baroclinic processes. This component of EP-flux includes the meridional transport of sensible heat, which has been discussed in further detail in May (1995).

In contrast to the barotropic processes the synoptic disturbances generally tend to counteract the changes in the mean circulation associated with the ENSO phenomenon (see Fig. 9c and 9d) via baroclinic processes (Fig. 16). During El Niño events, for instance, the transport of heat by the synoptic disturbances leads to a strengthening of the westerly winds over the northern Pacific, but also further downstream over Canada and particularly in the area of the Atlantic jet stream (Fig. 16a). Further south the short baroclinic disturbances cause a weakening of the mean westerly flow. During La Niña events, on the other hand, the synoptic dis- turbances generate easterly wind anomalies over the northern part of North America and westerly wind anomalies over the southeastern part of the north Pacific and over western North America (Fig. 16b). In the European region the distributions reveal a reduction of the westerly winds during the warm ENSO-events, but an enhancement during the cold events via baroclinic processes.

\section{Concluding Remarks}

In this paper we have undertaken a study of the impact of the pronounced positive and negative SST-anomalies in the tropical Pacific associated with the ENSO phenomenon on the atmospheric circulation in the Northern Hemisphere extratropics during the boreal winter season. This has included both the impact on the seasonal mean circulation and the impact on the intraseasonal variability on synoptic time scales. Moreover, we have studied the interaction between the transient fluctuations on these time scales and the mean circulation. This has been done in order to investigate, to which extent these fluctuations maintain or counteract the anomalous circulation patterns associated with the selected ENSOevents. We have used both operational analyses from ECMWF and data from an ensemble of five simulations with the ECHAM3 atmospheric 
GCM each covering the period 1979 through 1992, which includes three complete cycles of El Niño and La Niña events. In each of the simulations observed SSTs for the period of investigation have been given a lower boundary forcing, but different atmospheric initial conditions have been prescribed. By these means we have been able to assess the "external" variability caused by variations of the SSTs and the "internal" variability due to internal atmospheric processes, leading to an estimate of the potential predictability of the changes in the atmospheric circulation due to pronounced variations of the SSTs.

The simulations with ECHAM3 reveal a distinct impact of the pronounced SST-anomalies in the tropical Pacific on the atmospheric circulation in the Northern Hemisphere extratropics during El Niño as well as during La Niña events. These changes in the atmospheric circulation, which have been found to be highly significant in the Pacific/North American as well as in the Atlantic/European region, are consistent with the essential results obtained from the analyses. The following Table 1 gives a concise summary of the main results of our study.

The results presented here support the hypothesis of an ENSO-impact in the Atlantic/European area as proposed by e.g., Fraedrich (1994). According to Fraedrich et al. (1993) are climate anomalies similar (with regard to their location and magnitude) to those that have been observed during El Niño and La Niña events characterized by the development of a high and a low pressure cell over Europe. In the beginning an initial variation of the atmospheric pressure over Europe is induced by a stationary wavetrain, which has its origin in the region of cyclogenesis over the northwestern Atlantic and extends over the northern Atlantic into the European area. Later on non-linear interactions with the transient fluctuations lead to an intensification of the initial variation of the atmospheric pressure over Europe. In their study Fraedrich et al. (1993) speculated that the source of the stationary wave train is affected by processes originating further upstream over the northern Pacific and, hence, by the ENSO phenomenon.

On the basis of the results presented here we consider the intensification (reduction) of the Aleutian low and the simultaneous reduction (intensification) of the Icelandic low during El Niño and during La Niña events, respectively, to be the determining factor. Due to the intensification of the Aleutian low during El Niño events cold polar air masses are more frequently lead

Table 1.

Pacific/North America Atlantic/Europe

stat. response:

- El Niño TNH-pattern (pos. phase);

intensification of Aleutian low;

intensification and equatorward shift of the jet stream;

- La Niña PNA-pattern (neg. phase);

reduction of Aleutian low; zonal orientation of the flow; poleward shift and downstream extension of the jet stream; pos. anomalies of geop. height over Atlantic and neg. anomalies over Europe; reduction of Icelandic low; zonal orientation of the flow; reduction and equatorward shift of the jet stream;

neg. anomalies of geop. height over Atlantic and pos. anomalies over Europe; intensification of Icelandic low;

intensification, poleward shift and downstream extension of jet stream;

trans. response:

- El Niño

- La Niña equatorward shift of the stormtrack;

intensification and downstream extension of the stormtrack; reduction of the stormtrack; southern route of cyclones (Ireland and central Europe); intensification of the stormtrack;

northern route of cyclones

(Iceland and northern Europe); 
into the area over the northern Pacific, whereas warm maritime air masses arrive in North America (May, 1995). At the same time polar air masses are less frequently lead into the area over the northwestern Atlantic, where they are essential for the development of cyclones. During La Niña events, on the other hand, cold polar air masses arrive more often in North America and in the region of cyclogenesis over the northwestern Atlantic due to the reduction of the Aleutian low and the downstream extension of the Pacific jet stream. As a consequence cyclones develop more frequently over the northwestern Atlantic eventually leading to an intensification of the Icelandic low. We have found that the changes in the intensity of the Aleutian low during the ENSO-events are accompanied by an alteration of the transport of momentum caused by the short baroclinic waves over the North American continent in such a way that the synoptic disturbances maintain the changes in the mean circulation over the northwestern Atlantic, e.g. the variation of the intensity of the Icelandic low during El Niño as well as during La Niña events. The synoptic disturbances, however, may also play a more active role in the process of generating the anomalies of the mean circulation in the area over the western Atlantic associated with the ENSO phenomenon. During La Niña events, for instance, interactions with the short baroclinic waves in the entrance region over the North American continent may initiate the strengthening of the Atlantic jet stream and the subsequent changes in the atmospheric circulation in the Atlantic/European region.

Since ECHAM3 shows such a distinct atmospheric response to the ENSO phenomenon, the model is suitable for predicting the mean distributions of meteorological variables such as temperatures and precipitation in various parts of the globe on long-range (e.g., Brankovic et al., 1994). The results presented here have revealed a potential for predicting the changes in the atmospheric circulation in the Northern Hemisphere extratropics due to the pronounced variations of the SSTs in the tropical Pacific associated with the ENSO phenomenon. Considering the clear response of the baroclinic waves to these variations of the SSTs, one can also expect a potential for predicting variations of the atmospheric circulation in North America and Europe associated with pronounced variations of the SSTs in the northern Pacific and in the northwestern Atlantic, respectively. One should, however, take the models systematic errors into account, which may modify the characteristics (location and/or strength) of the atmospheric response to the variations of the underlying SSTs.

\section{Acknowledgments}

We would like to thank our colleagues from the MaxPlanck-Institute of Meteorology, namely Erich Roeckner, Monika Esch, Uwe Schulzweida and Klaus Arpe for providing the data from the simulations with ECHAM3.

\section{References}

Barnston, A. G., 1994: Linear statistical short-term climate predictive skill in the Northern Hemisphere. J. Climate, 7 , 1513-1564.

Barnston, A. G., Livezey, R. E., 1987: Classification, seasonality and persistence of low-frequency atmospheric circulation patterns. Mon. Wea. Rev., 115, 1083-1126.

Bengtsson, L., Arpe, K., Roeckner, E., Schulzweida, U., 1996: Climate predictability experiments with a general circulation model. Climate Dyn., 12, 261-278.

Bjerknes, J., 1969: Atmospheric teleconnections from the equatorial Pacific. Mon. Wea. Rev., 97, 163-172

Blackmon, M. L., 1976: A climatological spectral study of the $500 \mathrm{mb}$ geopotential height in the Northern Hemisphere. J. Atmos. Sci., 33, 1607-1623.

Blackmon, M. L., Lau, N.-C., 1980: Regional characteristics of the Northern Hemisphere wintertime circulation: A comparison of the simulation of a GFDL general circulation model with observations. J. Atmos. Sci., 37, 497-514.

Brankovic, C., Palmer, T. N., Ferranti, L., 1994: Predictability of seasonal atmospheric variations. J. Climate, 7 , $217-237$.

DKRZ, 1992: The ECHAM3 atmospheric general circulation model. Techn. Report No. 6, 184pp.

Essenwanger, O. M., 1986: Elements of statistical analysis. In: Landsberg, H. E., (ed.): World/Survey of Climatology, General Climatology. Vol. 1B. Amsterdam: Elsevier Science Publishers, 424 pp.

Fraedrich, K., 1994: An ENSO impact over Europe? A review. Tellus, 46A, 541-552.

Fraedrich, K., Bantzer, C., Burkhardt, U., 1993: Winter climate anomalies in Europe and their associated circulation in $500 \mathrm{hPa}$. Climate Dyn., 8, 161-175.

Fraedrich, K., Müller, K., 1992: Climate anomalies in Europe associated with ENSO extremes. Int. I. Climatol., 12, 25-31.

Fraedrich, K., Müller, K., 1993: Climatology of wavenumber-frequency spectra at $500 \mathrm{mb}$ height along $50^{\circ} \mathrm{N}$ during the $\mathrm{El}$ Niño/Southern Oscillation extremes. Meteorol. Zeitschrift, 2, 80-84. 
Gates, W. L., 1992: The atmospheric intercomparison project. Bull. Amer. Meteor. Soc., 73, 1962-1970.

Gibson, J. K., Kållberg, P., Uppala, S., Hernandez, A., Nomura, A., Serrano, E., 1997: ERA description. ECMWF Re-analysis Project Report Series No. 1, 72pp.

Hansen, A. R., Sutera, A., Venne, D. E., 1989: An examination of midlatitude power spectra: evidence for standing variance and the signature of El Niño. Tellus, 41A, 371384.

Hoerling, M. P., Blackmon, M. L., Ting, M., 1992: Simulating the atmospheric response in the 1985-87 El Niño cycle. J. Climate, 5, 669-682.

Horel, J. D., Wallace, J. M., 1981: Planetary scale phenomena associated with the Southern Oscillation. Mon. Wea. Rev., 109, 813-829.

Jenkins, G. M., Watts, D. G., 1968: Spectral Analysis and its Applications: San Francisco: Holden-Day, 525pp.

Kousky, V. E., Bell, G. D., Halpert, M. S., 1994: Climate Diagnostics Bulletin No. 94/10, 77pp.

Kumar, A., Hoerling, M. P., 1995: Prospects and limitations of atmospheric GCM climate predictions. Bull. Amer. Meteor. Soc., 76, 335-345.

Lau, N.-C., 1985: Modeling the seasonal dependence of the atmospheric response to observed El Niños in 1962-76. Mon. Wea. Rev., 113, 1970-1996.

Lau, N.-C., 1988: Variability of the observed mid-latitude storm tracks in relation to low-frequency changes of the circulation pattern. J. Atmos. Sci., 45, 2718-2743.

Lau, N.-C., Holopainen, E. O., 1984: Transient eddy forcing of the time-mean flow as identified by geopotential tendencies. J. Atmos. Sci., 41, 313-328.

Liebmann, B., Hartmann, D. L., 1982: Interannual variations of outgoing IR associated with tropical circulation changes during 1974-78. J. Atmos. Sci., 39, 11531162.

Livezey, R. E., Mo, K. C., 1987: Tropical-extratropical teleconnections during Northern Hemisphere winter. Part II: Relationships between monthly mean Northern Hemisphere circulation patterns and proxies for tropical convection. Mon. Wea. Rev., 115, 3115-3132.

May, W., 1995: Der Einfluß des El Niño/Southern Oscillation Phänomens auf die atmosphärische Zirkulation in den mittleren Breiten der Nordhalbkugel: Beobachtungen und Modellsimulationen. Max-Planck-Institut für Meteorologie Examensarbeit Nr. 33, 126pp.

May, W., 1996: ENSO and its relation to the prominent mode of atmospheric variability in the Northern Hemisphere extratropics. In: Staniforth, A., (ed.) Research Activities in Atmospheric and Ocean Modelling. CAS/JSC Working Group Numerical Experimentation Report No. 23, 7.377.38 .

Palmer, T. N., Anderson, D. L. T., 1994: The prospects of seasonal forecasting - A review paper. Quart. J. Roy. Meteor. Soc., 120, 755-793.
Philander, S. G., 1990: El Niño, La Niña and the Southern Oscillation. San Diego: Academic Press, 289pp.

Renwick, J. A., Wallace, J. M., 1996: Relationships between north Pacific wintertime blocking, El Niño, and the PNApattern. Mon. Wea. Rev., 124, 2071-2076.

Reynolds, R. W., 1988: A real time global sea surface temperature analysis. J. Climate, 1, 75-86.

Roeckner, E., Arpe, K., Bengtsson, L., Brinkop, S., Dümenil, L., Esch, M., Kirk, E., Lunkeit, F., Ponater, M., Rockel, B., Sausen, R., Schlese, U., Schubert, S., Windelband, M., 1992: Simulation of the present-day climate with the ECHAM model: Impact of model physics and resolution. MPI-Report No. 93, 172pp.

Ropelewski, C. E., Halpert, M. S., 1987: Global and regional scale precipitation and temperature patterns associated with the El Niño/Southern Oscillation. Mon. Wea. Rev., 115, 1606-1626.

Straus, D. M., Shukla, J., 1997: Variations of midlatitude transient dynamics associated with ENSO. J. Atmos. Sci., 54, 777-790.

Trenberth, K. E., 1986: An assessment of the impact of transient eddies on the zonal flow during a blocking episode using localized Eliassen-Palm flux diagnostics. J. Atmos. Sci., 43, 2070-2087.

Trenberth, K. E., 1992: Global analyses from ECMWF and atlas of 1000 to $10 \mathrm{mb}$ circulation statistics. NCAR Technical Note NCAR/TN-373+STR, 191pp.

van Loon, H., Madden, R. A., 1981: The Southern Oscillation. Part I: Global associations with pressure and temperatures in northern winter. Mon. Wea. Rev., 109, 11501162.

van Loon, H., Rogers, J. C., 1981: The Southern Oscillation. Part II: Associations with changes in the middle troposphere in the northern winter. Mon. Wea. Rev., 109, 11631168.

Walker, G. T., Bliss, E. W., 1932: World weather, V. Mem. Roy. Meteorol. Soc., 4, 53-84.

Walker, G. T., Bliss, E. W., 1937: World weather, VI. Mem. Roy. Meteorol. Soc., 4, 119-139.

Wallace, J. M., Gutzler, D. S., 1981: Teleconnections in the geopotential height field during the Northern Hemisphere winter. Mon. Wea. Rev., 109, 784-812.

Wallace, J. M., Lim, G.-H., Blackmon, M. L., 1988: Relationship between cyclone tracks, anticyclone tracks and baroclinic wave guides. J. Atmos. Sci., 45, 439-462.

Zebiak, S. E, 1990: Diagnostic studies of Pacific surface winds. J. Climate, 3, 1016-1031.

Author's address: Dr. Wilhelm May and Dr. Lennart Bengtsson, Max-Planck-Institute for Meteorology, Bundesstrasse 55, D-20146 Hamburg, Federal Republic of Germany. Present affiliation: Danish Meteorological Institute, Lyngbyvej 100, DK-2100 Copenhagen, Denmark. 